\title{
Referrals for Movement Disorder Surgery: Under-Representation of Females and Reasons for Refusal
}

\author{
M. Setiawan, S. Kraft, K. Doig, K. Hunka, A. Haffenden, M. Trew, S. Longman, \\ R. Ranawaya, S. Furtado, R.G. Lee, O. Suchowersky, Z.H.T. Kiss
}

\begin{abstract}
Objective: Referral of movement disorder patients for deep brain stimulation surgery was examined to determine whether referred patients were representative of gender proportions in our population, and reasons why patients do not proceed to surgery. Methods: Demographic information on referrals to the surgical program was retrospectively reviewed from our database and from a detailed chart review. Results: Although almost equal numbers of movement disorder patients are male and female, of the 91 patients referred for surgery, only $31 \%$ were female. Sixty-one percent of referred patients did not undergo surgery. Of these, the majority were denied for medical reasons, including cognitive decline (21\%), psychiatric concerns (5\%) and neurological reasons (42\%). Conclusions: Almost one-third of patients referred for movement disorder surgery were denied for medical reasons. This underscores the importance of evaluation of all potential patients by a multidisiplinary team to fully assess suitablity for stereotactic surgery. Interestingly, women were under-represented in those referred. In order that all appropriate patients have the opportunity to consider surgery, education of both physicians and patients, and different strategies to approach females regarding surgery may allow more patients to benefit from this treatment.
\end{abstract}

RÉSUMÉ: L’orientation des patients vers la chirurgie dans les troubles du mouvement: sous-représentation des femmes et raisons d'exclusion. Objectif: L'orientation des patients atteints de troubles du mouvement vers la neurochirurgie pour stimulation cérébrale profonde a été examinée afin de déterminer si la proportion de ces patients par sexe était représentative de cette proportion dans notre population et pourquoi un certain nombre de ces patients ne subissent pas l'intervention. Méthodes: Il s'agit d'une analyse rétrospective de l'information démographique sur les patients orientés en chirurgie contenue dans notre base de données et obtenue également d'une revue détaillée de dossiers. Résultats: Bien qu'un nombre presque égal d'hommes et de femmes soient atteints de troubles du mouvement, seulement $31 \%$ des 91 patients orientés en chirurgie étaient des femmes. La chirurgie n'a pas été effectuée chez soixante et un pour cent d'entre eux, la plupart du temps pour des raisons médicales, soit un déclin cognitif chez $21 \%$, des problèmes de nature psychiatrique chez $5 \%$ et de nature neurologique chez $42 \%$. Conclusions: Un peu moins du tiers des patients orientés vers la chirurgie pour un trouble du mouvement n'ont pas subi cette chirurgie pour des raisons médicales. Cette constatation souligne l'importance d'une évaluation globale par une équipe multidisciplinaire de tous les patients candidats à la chirurgie stéréotaxique. Il est intéressant de noter que les femmes étaient sous-représentées parmi les patients orientés vers la chirurgie. Pour que tous les patients éligibles aient la possibilité d'y avoir accès, l'éducation des médecins et des patients et des stratégies différentes pour rejoindre les femmes pourraient permettre à un plus grand nombre de patients d'en bénéficier.

Can. J. Neurol. Sci. 2006; 33: 53-57

Although deep brain stimulation (DBS) for movement disorders (MD) is an accepted option for selected patients who have failed maximal medical management, ${ }^{1,2}$ only a small number are referred and only a proportion of those proceed to the operating room. Furthermore, a gender imbalance in operated patients was suggested previously. ${ }^{3,4}$ Therefore, we sought to determine (i) if disproportionate numbers of males are referred compared to females, and (ii) why the patients referred for surgery failed to reach the operating room.

\section{Methods}

In March 2004, the University of Calgary Movement Disorders Clinic (MDC) patient database included 1598 patients with the potentially surgical conditions of dystonia (859 patients), tremor (451 patients) or Parkinson's disease (PD) (867 patients). From January 2001 to March 2004, 91 patients were referred to the Surgical Program - 59 individuals for Parkinson's

From the Department of Clinical Neurosciences (MS, SK, KD, KH, RR, SF, RGL, OS, ZHTK), Department of Psychology (AH, SL,), Department of Psychiatry (MT), University of Calgary, Foothills Hospital - Calgary Health Region, Calgary, AB, Canada.

ReCeived December 8, 2004. AcCePted in finAl Form August 26, 2005. Reprint requests to: ZHT Kiss, Rm 182A, Heritage Medical Research Building, 3330 Hospital Drive NW, Calgary, Alberta, T2N 4N1, Canada. 
disease, 17 for tremor, six for cervical dystonia and nine for other conditions such as multiple sclerosis tremor and tardive dyskinesia. Of these 91 patients, 15 were still in screening as of June 2004. Among the remaining 76 patients, six were eliminated from analysis because their current status was unknown (these were patients referred from another province and may have decided to undergo surgery elsewhere). We focused on the remaining 70 patients in this retrospective study. Table 1 illustrates the breakdown of the 91 patients referred and the 1598 patients in the MDC database into the type of movement disorder and proportion of male and female patients.

The MDC Surgical program was multidisciplinary with all patients being examined by a neurologist (who often was not the primary treating neurologist) and neurosurgeon. Detailed neuropsychological assessment was performed on all patients and a dedicated neuropsychiatrist saw all patients at risk for mood or perceptual difficulties. Consultants participated in monthly meetings, discussing patients referred and outcomes. There were 12 referring doctors, of which three were female. Most $(71 \%)$ referrals came from the subspecialized movement disorder neurologists within the clinic.

Selection criteria for surgery used by our clinic were similar to others. ${ }^{1,5}$ Indications for surgery included failure of optimal medical management resulting in disability with significant impact on quality of life. The patients had no medical contraindication to surgery (e.g. bleeding diathesis or cardiac risk), no dementia, no significant brain atrophy on imaging, and were able to cooperate with surgery and ongoing follow-up. For PD patients, only those with levodopa-responsive idiopathic Parkinsonism, with disabling ON-OFF fluctuations or dyskinesia, failure of adequate trials of dopaminergic medications, or disabling PD tremor not relieved with medication were selected. Patients with a chief complaint not expected to improve significantly with surgery were also excluded. Cut-off in this cohort for subthalamic nucleus (STN) surgery was age $70^{1,6,7}$ and for pallidal or thalamic surgery, age $80 .^{8,-10}$ In patients with multiple sclerosis tremor, those with predominant limb ataxia were excluded. ${ }^{11,12}$

We first compared proportion of males and females referred, to those in our MDC database. We then examined why patients referred did not proceed to surgery and categorized the reasons into medical or personal ones. Statistical analyses included t-tests to compare characteristics of patient groups and z-tests to compare proportions (SigmaStat, SPSS). Data are reported as mean \pm standard deviation $(\mathrm{SD})$.

\section{Results}

Among the 91 patients referred for surgery, 63 were male $(69 \%)$ and 28 were female $(31 \%)$. In the MD population with a potentially surgical condition $(\mathrm{N}=1598), 53 \%$ were male and $47 \%$ were female. Thus compared to the total catchment population, there was a significant under-representation of females $(\mathrm{z}=2.87, \mathrm{P}=0.004)$. Most of this referral bias arose from the MDC itself (20\% female: $80 \%$ male patients referred) and not from outside the Calgary MDC (57.7\% female: $42.3 \%$ male patients referred).

Of the 70 patients referred and for whom outcome was known, 27 (39\%) have undergone the procedure within the last three years and $43(61 \%)$ had reasons to forego surgery. Of these 27 patients who proceeded with surgery, 24 were male and three were female. Among those not having surgery, the main reasons were of a medical nature: 18 (42\%) had a neurological reason, such as unclear diagnosis (concern about a Parkinson's plus syndrome), inadequate trial of medications, or chief complaint not amenable to surgery, two $(5 \%)$ had psychiatric issues (such as gambling or episode of severe depression in the past) and nine (21\%) had cognitive decline as assessed by mini-mental status examination (MMS < 24/30) or neuropsychological testing. The remaining 14 (33\%) declined surgery for personal reasons. These reasons included concerns from either the patient or the spouse regarding the risks of surgery once discussed and presented. Others learned of the awake procedure and were not comfortable with this. Some found the travel required for ongoing programming and follow-up too arduous based on personal circumstances.

There was no gender difference in the proportion of referred patients not undergoing surgery (57\% of females, $43 \%$ of males; $\mathrm{Z}=1.03, \mathrm{P}=0.30)$. Whereas more females than males did not have surgery for medical reasons, this did not achieve statistical significance $(88 \%$ of all referred females not having surgery, $56 \%$ of all males not having surgery; $\mathrm{z}=1.82, \mathrm{P}=0.07)$. There was no significant difference in age at referral (males, $58.7 \pm$

Table 1: Breakdown by gender and movement disorder for patients in the University of Calgary Movement Disorder Clinic database and breakdown by movement disorder of patients referred for surgery from January 2001 to March 2004

\begin{tabular}{|c|c|c|c|c|}
\hline U of C MDC Database & Males & Females & Total & Patients referred \\
\hline Parkinson's & 500 & 367 & 867 & 59 \\
\hline Dystonia & 144 & 136 & 280 & 6 \\
\hline Tremor & 207 & 244 & 451 & 17 \\
\hline Other (e.g. MS tremor, tardive dyskinesia) & N/A & N/A & --- & 9 \\
\hline TOTAL & 851 & 747 & 1598 & 91 \\
\hline
\end{tabular}


Table 2: Summary of male and female patients referred for surgery and compared to entire population of potential surgical patients.

\begin{tabular}{|c|c|c|c|}
\hline & Female & Male & Total \\
\hline MD clinic database (includes tremor, PD, dystonia) & $747(47 \%)$ & $851(53 \%)$ & 1598 \\
\hline Referred for deep brain stimulation surgery (Feb 01-Mar 04) & $28(31 \%)^{*}$ & $63(69 \%)^{*}$ & 91 \\
\hline $\begin{array}{l}\text { Those NOT proceeding to surgery (total includes only those in whom } \\
\text { outcome is known, see text) }\end{array}$ & 16 & 27 & 43 \\
\hline \multicolumn{4}{|l|}{ Reasons for NOT proceeding with surgery } \\
\hline Medical & $14(88 \%) \ddagger$ & $15(56 \%) \dagger$ & $29(67 \%)$ \\
\hline Personal & $2(13 \%) \ddagger$ & $12(44 \%)$ & $14(33 \%)$ \\
\hline
\end{tabular}

Percentages shown in brackets on top two lines indicate the proportion of males vs. females in the MD clinic database. There is a significant difference in females vs. males referred from the base population ( $* \mathrm{z}=2.87, \mathrm{P}=0.004)$. Whereas in both males and females approximately $60 \%$ did not proceed to surgery, their reasons differed. More females did not have surgery for medical reasons than personal ones $(+\mathrm{z}=4.44, \mathrm{P}<0.001)$ whereas of the males not having surgery, the reasons were evenly divided among medical and personal $(\dagger \mathrm{z}=0.36, \mathrm{P}=0.72)$. Percentages in lower lines indicate the proportion with medical vs. personal reasons for not proceeding to surgery.

15.6; females, $56.1 \pm 14.0 ; \mathrm{t}=0.51, \mathrm{P}=0.61)$, Hoehn \&Yahr stage $\mathrm{ON}$ medication (males $2.2 \pm 0.5$; females $2.5 \pm 0.4 ; \mathrm{t}=$ $1.15, \mathrm{P}=0.27$ ) and time from diagnosis to referral (males $14.1 \pm$ 12.1 years; females $15.2 \pm 11.0$ years; $\mathrm{t}=0.28, \mathrm{P}=0.78$ ). Table 2 summarizes the reasons for not proceeding to surgery and compares referral rates in females and males in comparison to the MD population.

\section{Discussion}

Several conclusions can be drawn from these data. First, fewer females were referred for surgery on the basis of the population with surgically treatable MD. Second, despite receiving referrals from mainly subspecialized movement disorder neurologists, $61 \%$ of patients did not have surgery and of these, two-thirds were rejected for the following medical reasons: inadequate medication trials, unclear diagnosis, symptoms not amenable to surgery, psychiatric illness or cognitive decline.

The first conclusion suggests a gender bias in referral. Because our MDC captures most potential patients in southern Alberta and there is no functional neurosurgery outside our university centre, we are confident that all potential patients in our 1.5 million population have been counted. Because there is a roughly equal proportion of males and females with $\mathrm{PD}$ in Alberta, ${ }^{13}$ our clinic population of potential surgical referrals was similar, and most referrals were for PD, we anticipated a fairly equal proportion of male and female referrals.

While our study involves only one centre, review of the published literature revealed that fewer females undergo MD surgery than males, ${ }^{3}$ and females who do have surgery are operated on later in their disease. ${ }^{4}$ A potential reason for this is differential progression of disease in the sexes: one study reported that males with PD have more rapid progression of their Unified Parkinson's disease Rating Scale (UPDRS) Parts I-II than females. ${ }^{14}$ This is unlikely to have produced a large enough effect to account for our results because the UPDRS alone is not a selection criteria for surgery. However because Parts I-II involve patient reporting of their condition it may reflect males feeling more disabled earlier in the course of PD.

Gender bias occurs in other aspects of medicine ${ }^{15}$ with females not offered as aggressive treatment for $\operatorname{cardiac}^{16}$ or gastrointestinal conditions. ${ }^{17}$ Reasons for these gender differences are speculative: neurologists may not discuss surgical options with females early in the course of their disease or females may be better at coping with PD for longer. ${ }^{4}$ Women may view surgery as a high-risk activity or simply decide early, before the referral is made, that they would not consider surgery. This may potentially account for why more males were referred but then refused to proceed for personal reasons. Males may view themselves as the financial provider to the family and thus may be more active in seeking more aggressive treatment. While there are no data to confirm this, we observed that wives attend appointments with their ill husbands and play a proactive role in their medical conditions, whereas fewer husbands attend appointments with their wives affected by PD. Another potential cause of gender bias is the sex of the physicians involved in patient referral, although this has only been previously reported for gender-specific (breast reconstruction) surgery. ${ }^{18}$

Second, a majority of patients referred for surgery were not felt to be suitable candidates for a number of medical, neurocognitive and psychiatric reasons. This underscores the importance that these patients receive detailed evaluation by a multidisciplinary team. An example would be a case where an independent physician suggested changes in a patient's medication combinations, improving symptoms in someone previously reluctant to try new drugs, and thereby obviating the need for surgery. In some patients, a Parkinson's plus syndrome was thought to be more likely than idiopathic PD by the second 
neurologist or neurosurgeon. Some patients were referred by their primary neurologist with an appropriate surgical condition but when reviewed by the surgical team these patients were not offered surgery unless they complained of a surgically responsive symptom. As for determination of cognitive decline, this was determined by neuropsychological testing in patients who appeared to be functioning fairly well in office visits. The multidisciplinary team asks many detailed questions, regarding presence and extent of gambling and depression. These issues are not routinely addressed in office neurological practice, but when present, are potential contraindications for STN surgery if left untreated. ${ }^{19,20}$

Whereas it is the role of the referring neurologist to diagnose and attempt full medical treatment before seeking surgical consultation, patients often have unrealistic expectations and request surgical consultation even at the dissuasion of their treating neurologist. The importance of patient expectation has been reported in movement disorder surgery ${ }^{12}$ and is also observed among patients who consider undergoing other elective surgical procedures. ${ }^{21,22}$ Some of our patients could therefore represent individuals who underwent screening as a method of seeking a second opinion either from the neurosurgeon or another movement disorder neurologist. This is not unreasonable, as it is expected that the surgical team discuss most comprehensively all risks and benefits of surgery. The group who declined surgery did so upon learning more about the procedure. These patients, along with those who request surgical consultation on their own, may feel better equipped to make a decision once they meet with the surgical team. As for the 14 patients who declined surgery for personal reasons, 12 were male. This may indicate that males are more likely to consider surgery before declining, whereas females may presume risk and reject the suggestion earlier on.

Surgery for movement disorders is an elective procedure for which, after meeting appropriate selection criteria, patients ultimately must decide if the procedure is worth the risk. Only a small proportion are currently being referred, and of these, about two-thirds do not have surgery, and one-third may not even be appropriate candidates. Whereas selection criteria for referral exists in the literature, such studies usually include only perfect homogenous patient groups. Unfortunately patients are rarely perfect candidates and clinical judgement is required to determine who will achieve benefit with surgery. Appropriate surgical candidates who decline surgery brings into question the method by which the option of surgery is presented. Presenting the possibility of surgery at a different stage in a patient's disease, or offering more support regarding decision-making from an earlier stage, may change decision outcome and is a potential topic for further study. Given the gender bias observed in this study, one could speculate whether females interpret the information provided differently than males.

Study of those patients who are not referred and those who are referred but do not have surgery is as important as study of those who do. We believe that establishing standardized criteria for surgical referral for movement disorders and informing referring neurologists about potential gender bias, in addition to developing a novel strategy to recruit females, may allow more patients to benefit from surgery at a treatable stage of their disease.

\section{ACKNOWLEDGEMENTS}

Funding for this work was provided by the Alberta Heritage Foundation for Medical Research (AHFMR) and the Canadian Institutes for Health Research (CIHR). Dr. Kiss is a CIHR Clinician-Scientist and an AHFMR Clinical Investigator. Dr. Kraft was a Parkinson Society of Canada Clinical Fellow. We also thank Mrs. Marlene Conrad for expert clerical assistance.

\section{REFERENCES}

1. Krack PP, Batir A, Van Blercom N, Chabardes S, Fraix V, Ardouin $\mathrm{C}$, et al. Five-year follow-up of bilateral stimulation of the subthalamic nucleus in advanced Parkinson's disease. N Engl J Med. 2003; 349[20]: 1925-34.

2. Schuurman PR, Bosch DA, Bossuyt PMM, Bonsel GJ, Van Someren EJW, de Bie RM, et al. A comparison of continuous thalamic stimulation and thalamotomy for suppression of severe tremor. N Engl J Med. 2000; 342[7]: 461-8.

3. Hariz G, Hariz MI. Gender distribution in surgery for Parkinson's disease. Parkinsonism Relat Disord. 2000; 6[3], 155-7.

4. Hariz GM, Lindberg M, Hariz MI, Bergenheim AT. Gender differences in disability and health-related quality of life in patients with Parkinson's disease treated with stereotactic surgery. Acta Neurol Scand. 2003; 108[1]: 28-37.

5. Vercueil L, Krack PP, Pollak P. Results of deep brain stimulation for dystonia: A critical reappraisal. Mov Disord. 2002; 17[Suppl 3]: S89-S93.

6. Russmann H, Ghika J, Villemure JG, Robert B, Bogousslavsky J, Burkhard PR, et al. Subthalamic nucleus deep brain stimulation in Parkinson disease patients over age 70 years. Neurology. 2004; 63[10]: 1952-4.

7. Welter ML, Houeto JL, Tezenas du Montcet S, Mesnage V, Bonnet AM, Pillon B, et al. Clinical predictive factors of subthalamic stimulation in Parkinson's disease. Brain. 2002; 125[Pt 3]: 575-83.

8. Tröster AI, Fields JA, Pahwa R, Wilkinson SB, Straits-Tröster KA, Lyons K, et al. Neuropsychological and quality of life outcome after thalamic stimulation for essential tremor. Neurology. 1999; 53: $1774-80$.

9. Herrera EJ, Viano JC, Caceres M, Costello G, Suarez M, Suarez JC. Posteroventral pallidotomy in Parkinson's disease. Acta Neurochir. (Wien.) 2000; 142[2]: 169-175.

10. Uitti RJ, Wharen RE, Jr., Turk MF, Lucas JA, Finton MJ, GraffRadford NR, et al. Unilateral pallidotomy for Parkinson's disease: comparison of outcome in younger versus elderly patients. Neurology. 1997; 49[4]: 1072-7.

11. Liu X, Aziz TZ, Miall RC, Rowe J, Alusi SH, Bain PG, et al. Frequency analysis of involuntary movements during wrist tracking: a way to identify MS patients with tremor who benefit from thalamotomy. Stereotact Funct Neurosurg. 2000; 74[2]: 5362.

12. Berk C, Carr J, Sinden M, Martzke J, Honey CR. Thalamic deep brain stimulation for the treatment of tremor due to multiple sclerosis: a prospective study of tremor and quality of life. J Neurosurg. 2002; 97[4]: 815-20.

13. Svenson LW, Platt GH, Woodhead SE. Geographic variations in the prevalence rates of Parkinson's disease in Alberta. Can.J Neurol Sci. 1993; 20[4]: 307-11.

14. Jankovic J, Kapadia AS. Functional decline in Parkinson disease. Arch.Neurol. 2001; 58[10]: 1611-5.

15. Council on Ethical and Judicial Affairs AMA. Gender disparities in clinical decision making. JAMA. 2004; 266[4]: 559-62.

16. Schulman KA, Berlin JA, Harless W, Kerner JF, Sistrunk S, Gersh $B J$, et al. The effect of race and sex on physicians' recommendations for cardiac catheterization. N Engl J Med. 1999; 340[8]: 618-26. 
17. Herold AH, Riker AI, Warner EA, Woodard LJ, Brownlee HJ, Jr., Pencev D, et al. Evidence of gender bias in patients undergoing flexible sigmoidoscopy. Cancer Detect.Prev. 1997; 21[2]: 141-7.

18. Wanzel KR, Brown MH, Anastakis DJ, Regehr G. Reconstructive breast surgery: referring physician knowledge and learning needs. Plast Reconstr Surg. 2002; 110[6]: 1441-50.

19. Burkhard PR, Vingerhoets FJ, Berney A, Bogousslavsky J, Villemure JG, Ghika J. Suicide after successful deep brain stimulation for movement disorders. Neurology. 2004; 63[11]: 2170-2.
20. Houeto JL, Mesnage V, Mallet L, Pillon B, Gargiulo M, du Moncel ST, et al. Behavioural disorders, Parkinson's disease and subthalamic stimulation. J Neurol Neurosurg Psychiatry. 2002; 72[6]: 701-7.

21. Eisler T, Svensson O, Tengstrom A, Elmstedt E. Patient expectation and satisfaction in revision total hip arthroplasty. J Arthroplasty. 2002; 17[4]: 457-62.

22. McGregor AH, Hughes SP. The evaluation of the surgical management of nerve root compression in patients with low back pain: Part 2: patient expectations and satisfaction. Spine. 2002; 27[13]: 1471-6. 